\title{
The procedure in the classroom setting by which nursing faculty construct academic accommodations for undergraduate nursing students with learning disabilities: A scoping review
}

\author{
Amy Yarbrough* \\ University of West Georgia, Carrollton, GA, USA
}

Received: May 24, 2019

DOI: $10.5430 /$ jnep.v10n1p85
Accepted: September 9, 2019

Online Published: September 29, 2019

\begin{abstract}
Background and objective: A scoping review was conducted to determine what is currently known about the procedure in the classroom setting by which nursing faculty construct academic accommodations for undergraduate nursing students with learning disabilities. The number of nursing students with disabilities is growing, and nursing students with identified learning disabilities require academic accommodations to facilitate their success. Effective understanding of the academic accommodation procedure by faculty is necessary to promote student success and inclusive learning environments within nursing education.

Methods: The framework from Arksey and O'Malley was used to identify gaps in the literature related to the procedure in the classroom setting by which nursing faculty construct academic accommodations for students with learning disabilities.

Results: The themes of faculty attitude, previously used accommodations, and lack of understanding of the procedure of accommodation implementation were derived from the literature.

Conclusions: Current research fails to adequately answer the research question related to the procedure by which nursing faculty in the classroom setting construct academic accommodations for students with learning disabilities. Further research into the procedure by which faculty make academic accommodations in the nursing education classroom is needed.
\end{abstract}

Key Words: Learning disability, Nursing education, Accommodations, Student with disabilities, Accommodations process, Nursing faculty

\section{BACKGROUND}

In recent years, an increased number of students with identified disabilities are entering higher education seeking degrees. ${ }^{[1,2]}$ Students with disabilities represent approximately $11 \%$ of the higher education student population. ${ }^{[2]}$ Within the higher education student population, learning disabilities comprise $31 \%$ of all disabilities reported by institutions. ${ }^{[2]}$ While increased numbers of students with learning disabili- ties are reported, so are descriptions of difficulties with academic accommodations. ${ }^{[3-6]}$ Experiencing difficulties with academic accommodations correlates with negative student success in obtaining a degree. ${ }^{[3,4,7]}$ Furthermore, several studies consistently reported a correlation between faculty lack of knowledge of academic accommodation procedure practices to the ineffective provision of help to students with disabilities. ${ }^{[3,8,9]}$ Unfortunately, higher education literature

*Correspondence: Amy Yarbrough; Email: ayarbrou @ westga.edu; Address: University of West Georgia, Carrollton, GA, USA. 
focuses on the effectiveness of specific accommodations for specific learning disabilities, little is known about the procedure for making the academic accommodations.

In addition to an increased number of students with identified disabilities entering higher education, health professions such as nursing are also noting an influx of students with disabilities. ${ }^{[1,2,6,11-13]}$ Learning disabilities are the most prevalent disability noted within higher education as well as in nursing education. ${ }^{[2,8,12,14-17]}$ This increased prevalence results from legislative changes in higher education creating expanded access to nursing education for students with disabilities. However, while students with learning disabilities are increasing, successful completion of programs is decreasing. ${ }^{[2]}$ Additionally, students with learning disabilities continue to be underrepresented in nursing education as historically nursing education has excluded students with disabilities. $^{[11,15,18-22]}$

Since the population of nursing students with disabilities is primarily comprised of students with learning disabilities, it is imperative for nursing faculty to understand how to promote success within this population. ${ }^{[15]}$ While nursing faculty has a high percentage of being exposed to students with learning disabilities, a lack of understanding exists regarding the procedure for how to provide academic accommodations to promote student success with this type of disability. ${ }^{[14,15,17,19]}$ Additionally, nursing faculty contribute the lower percentages of nursing students with disabilities to the negative faculty perceptions and a lack of faculty understanding of disabilities, accommodations, and resources. ${ }^{[18-20,23]}$ Furthermore, the procedure of academic accommodations for nursing students with learning disabilities has not been examined within nursing literature. Therefore, an understanding of the procedure in the classroom setting by which nursing faculty make academic accommodations for undergraduate nursing students with learning disabilities is necessary.

Academic accommodations are primarily assigned to nursing students with disabilities at the discretion of the institution's disability services office. Students with learning disabilities are more successful with the use of disability services. ${ }^{[16,24]}$ Research has documented that students with learning disabilities face additional challenges in nursing education. ${ }^{[20,21,23]}$ Students with learning disabilities often require additional educational interventions to be successful in nursing education. These interventions, referred to as academic accommodations, provide students with an equal opportunity of success when compared to non-disabled students. ${ }^{[17,20,21,25]}$ However, faculty's understanding of the procedure and implementation of academic accommodations could inhibit or promote the use of such services. ${ }^{[16]}$ Unfortunately, a scarcity of literature inhibits nursing faculty to promote services for successful inclusion of students with learning disabilities in the classroom. Therefore, it is important to identify nursing literature to assist with understanding the procedure in the classroom setting by which nursing faculty construct academic accommodations for undergraduate nursing students with learning disabilities.

\section{KNOWLEDGE SYNTHESIS METHOD}

A scoping review of the literature was performed to determine the extent of literature available in relation to the procedure in the classroom setting by which nursing faculty construct academic accommodations for students with learning disabilities. A scoping review is an assessment of the scope of available literature surrounding a topic to identify a need in a research area that has not been comprehensively reviewed. ${ }^{[26,27]}$ Scoping reviews allow for a broad understanding and exploration of a phenomenon and all relevant literature pertaining to the phenomenon. ${ }^{[26]}$ This scoping review followed Arksey and O'Malley's ${ }^{[26]}$ methodology and framework and includes quantitative, qualitative, and mixed methods research as well as non-research articles and grey literature. Arksey and O'Malley's ${ }^{[26]}$ framework includes five steps: (a) identifying the research question, (b) identifying relevant studies, (c) study selection, (d) charting the data, and (e) summarizing results.

\subsection{Identifying the research question}

The first step in a scoping review is to identify the research question. ${ }^{[26]}$ This scoping review was conducted to answer the following question: What is known from the existing literature regarding the procedure in the classroom setting by which nursing faculty construct academic accommodations for undergraduate nursing students with learning disabilities?

\subsection{Identifying relevant studies}

The second step in a scoping review is to identify sources relevant to the research question. ${ }^{[26]}$ Consistent with Arksey and O'Malley's ${ }^{[26]}$ methodology, multiple comprehensive searches through multiple sources were conducted from May 2017 to August 2017 to locate all relevant articles. Electronic databases, reference lists from related writings, and web-based searches consisted of broad language to include all relevant literature related to the topic. The same or similar combinations of key words were used to search the electronic databases and the internet. The key search terms utilized can be found in Table 1 . 
Table 1. Search terms

\begin{tabular}{ll}
\hline Search Terms & Search Limiters \\
\hline $\begin{array}{l}\text { Nursing Education } \\
\text { Learning Disability or }\end{array}$ & Written in English \\
$\begin{array}{l}\text { Mental Impairment } \\
\text { Academic Adjustment or }\end{array}$ & Published between 2008-2017* \\
$\begin{array}{l}\text { Academic Accommodation } \\
\text { Nursing Student }\end{array}$ & \\
$\begin{array}{l}\text { College or University or } \\
\text { Higher Education }\end{array}$ & \\
\hline *With exception of two articles published in 2006
\end{tabular}

Electronic databases, reference lists, and internet-based searches were examined through an iterative process to complete a thorough search of the relevant literature. Electronic databases included CINAHL: Nursing and Allied Health, ProQuest Nursing and Allied Health Source, Health Source: Nursing/Academic Edition at EBSCOhost, and MEDLINE (with Full Text) at EBSCOhost. In electronic databases, searches were limited to the search years of 2008-2017 as regulations governing students with disabilities in higher education took effect in 2009. ${ }^{[25]}$ However, two studies published in 2006 were discovered and included as the only articles that pertained specifically to students with learning disabilities in the classroom setting of nursing education. Grey literature was not eliminated, and the selected relevant articles reference lists underwent reviews by hand; they were also limited to the search years of 2008-2017. Google and Google Scholar were also utilized with multiple attempts of various word transitions searched related to the topic. All searches were limited to resources that were published in English.

\subsection{Study selection}

In the study selection step, inclusion and exclusion criteria are examined and applied in relation to the search results. ${ }^{[26]}$ In total, 800 articles were identified from database searches. Titles and abstracts were reviewed, and several articles were noted on health care disciplines other than nursing, international literature, physical disabilities, higher education, secondary education, practicing nurses and nursing students working with patients with learning disabilities. After exclusion criteria were applied, 40 articles were maintained for further review based on the inclusion criteria displayed in Table 2.

Articles retrieved from web searches and reference lists were also reviewed based on inclusion and exclusion criteria. Twenty-seven articles remained that addressed implementation of academic accommodations. Only articles that met all inclusion criteria and contributed valuable information to the research question where chosen for inclusion. Figure 1 diagrams the study selection process.

Table 2. Inclusion and exclusion criteria

\begin{tabular}{ll}
\hline Inclusion Criteria & Exclusion Criteria \\
\hline Studied Nursing & International Literature \\
Classroom Education & Studied Nursing Students \\
with Learning Disabilities & $\begin{array}{l}\text { Literature on Physical Disabilities in } \\
\text { Nursing Education }\end{array}$ \\
Addressed Academic & Literature on Secondary Education \\
Accommodations & or Transition to Higher Education \\
Conducted in the United & $\begin{array}{l}\text { Literature on Nurses and Nursing } \\
\text { Students Working with Disabled }\end{array}$ \\
& Patients \\
\hline
\end{tabular}

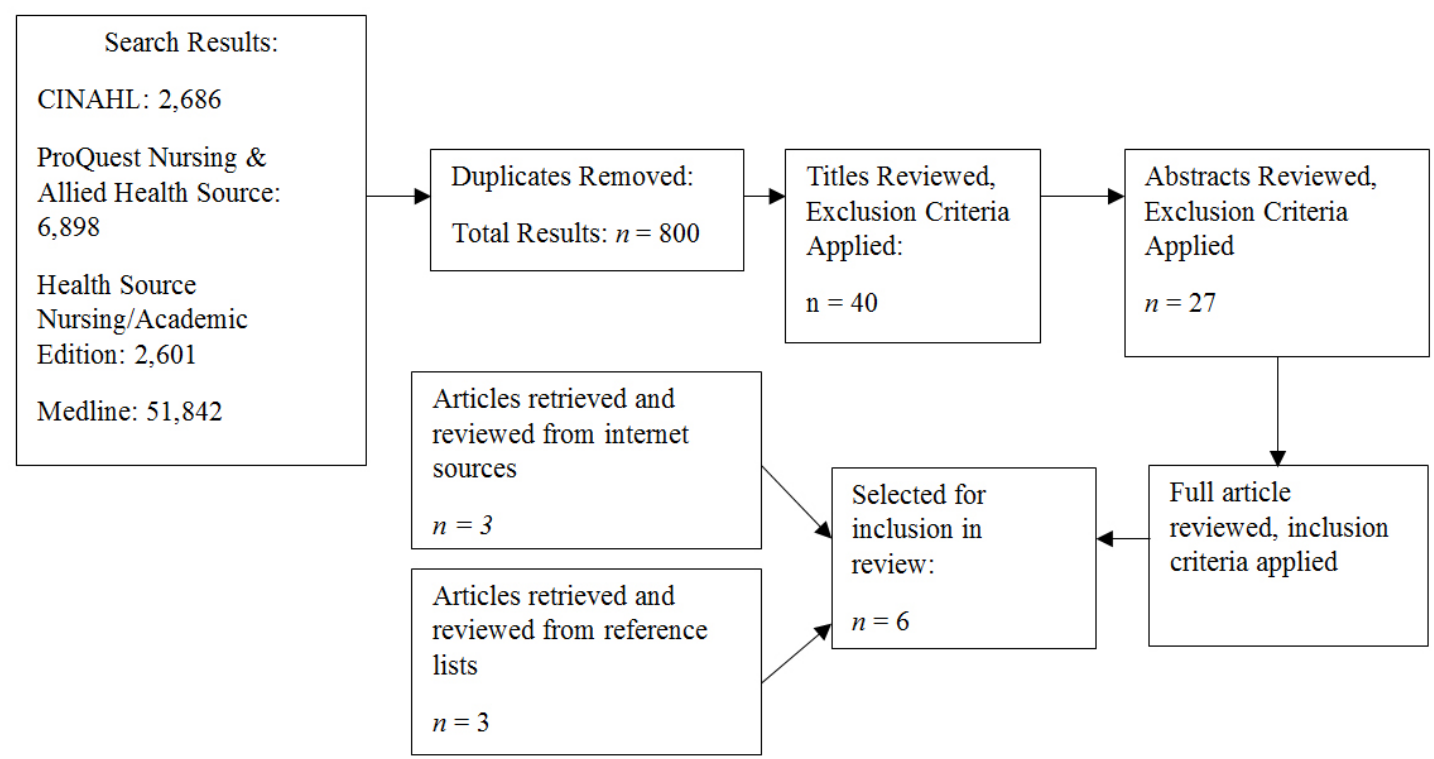

Figure 1. Study selection process 


\subsection{Charting the data}

The fourth step in the scoping review process is to chart the data. Charting the data requires an examination of the selected articles to extract pertinent issues. ${ }^{[26]}$ The pertinent issues are then scrutinized for themes or connections within the articles. ${ }^{[26]}$ Complete results from data charting are located in the appendix. A narrative approach was used, as recommended by Arksey and O'Malley, ${ }^{[26]}$ to allow for a broad inclusion of resources related to classroom accommodations and students with learning disabilities in nursing education.

\section{RESULTS}

After charting the relevant information from acquired literature, the last step in the scoping review process involves reporting the findings and themes to draw conclusions from the literature and answer the research question. ${ }^{[27]}$ Three themes were identified from the relevant literature with the use of qualitative thematic analysis. Thematic analysis is the most appropriate method for quantifying results and identifying themes in a scoping review. ${ }^{[28]}$ The article abstracts were analyzed, resulting in the creation of themes. The thematic analysis uncovered three themes related to the research question. The themes of faculty attitude, previously used academic accommodations, and lack of understanding of the procedure of academic accommodation implementation provide valuable insight into the research question and include support for understanding the procedure in the classroom setting by which nursing faculty construct academic accommodations for students with learning disabilities.

\subsection{Faculty attitude}

The facilitation of academic accommodations in a classroom setting for students with learning disabilities requires a positive faculty attitude. Nursing faculty attitudes and beliefs towards students with learning disabilities greatly impact student success as well as student perceptions of acceptance. ${ }^{[8,17,22]}$ Positive faculty attitudes towards students with learning disabilities correlated with an increase in students seeking academic accommodations, faculty compliance with accommodation practices, and faculty having increased knowledge of learning disabilities. ${ }^{[8,9,14,17,22]}$

Increased faculty knowledge of academic accommodation practices for students with learning disabilities enhanced students seeking and using accommodations within the classroom setting. ${ }^{[22]}$ The request and use of academic accommodations by students have been positively associated with student academic success. ${ }^{[16,22,24]}$ However, students may resist seeking academic accommodations because of negative faculty attitudes. ${ }^{[9,22]}$
Negative attitudes correlate with a knowledge deficit by faculty of different learning disabilities as well as the procedure for academic accommodations for students with disabilities. ${ }^{[21,23]}$ This knowledge deficit translates into a failure of nursing faculty to consistently provide academic accommodations due to perceived ineffectiveness of use. ${ }^{[9,29]}$ Additionally, Levey ${ }^{[17]}$ discovered varying degrees of the small knowledge held by faculty for the understanding of the procedure and applicability of academic accommodations among nursing faculty. The variability of faculty understanding of the accommodation procedure contributed to negative faculty attitudes and inconsistency with accommodation implementation. The frequent use and understanding of the procedure for academic accommodations enhanced faculty's adherence to use and perception of the effectiveness of accommodations. ${ }^{[9,17,20]}$

Negative faculty attitudes are also associated with student resistance to seek academic accommodations. ${ }^{[9,22,29]}$ Nursing students often do not seek academic accommodations based on the perception that nursing faculty associated a disability with a lack of intelligence. ${ }^{[22]}$ Additionally, fear of retribution by the faculty and the refusal to grant academic accommodations inhibited students from seeking academic accommodations. ${ }^{[22]}$

Burgstahler and Doe ${ }^{[30]}$ discovered that nursing faculty understood physical disabilities more than learning disabilities and were more willing to provide accommodations for students with physical disabilities compared with learning disabilities. Therefore, faculty knowledge about learning disabilities and academic accommodations is essential to student success. Therefore, to understand the current procedure in the classroom setting by which nursing faculty construct academic accommodations for students with learning disabilities is essential to a positive faculty attitude regarding accommodations.

\subsection{Previously used academic accommodations}

While previously used accommodations are noted within the nursing education literature, there is a lack of research supporting or explaining the procedure for implementing academic accommodations for students with learning disabilities that would be effective within the classroom setting. ${ }^{[14]}$ Kolanko $^{[31]}$ described effective academic accommodations from student perspectives with a learning disability that assisted learning. Additionally, Ardary ${ }^{[14]}$ focused on nursing faculty experiences with students with learning disabilities. A paucity of literature exists regarding learning disabilities in nursing education and the implementation of an effective procedure for academic accommodations. While working with students on an individual basis and early intervention with 
the use of academic accommodations are emphasized within the literature, not one source provided a specific outline or demonstrated effectiveness for this procedure.

Betz et al. ${ }^{[15]}$ discovered that the most frequently requested and received accommodations by nursing students were classroom related. Regularly provided classroom accommodations were extended testing time, extended assignment completion time, provision of a quiet environment during testing, adaptive technology, preferential classroom seating, and note takers. ${ }^{[8,15,29]}$ Cawthon and Cole ${ }^{[8]}$ discovered students in the higher education environment rated note takers, extended time on tests, adaptive technology, and preferential classroom seating as being more effective academic accommodations than alternative testing environments. With varying effectiveness of accommodations, perhaps an understanding of the academic accommodation procedure remains unclear. However, increased faculty understanding of the academic accommodation procedure improved faculty confidence and willingness to properly accommodate students with disabilities in the classroom setting. ${ }^{[8,29]}$

Meloy and Gambescia ${ }^{[23]}$ attempted to assist faculty with the current process of academic accommodations by providing examples of academic accommodation requests followed by suggestions for best practice. The scenarios consisted of nursing faculty who encounter students that appear to have the intellectual ability but struggle with course content even after multiple mentoring or tutoring sessions by faculty. Faculty's time-intensive interventions of reviewing course content and multiple tutoring sessions may not address learning comprehension issues. ${ }^{[23]}$ The student issues related to learning comprehension may underlie a learning disability beyond the scope of faculty expertise, which delays appropriate academic accommodations to help students be successful. ${ }^{[23]}$ Nursing faculty need to be in close collaboration with the disabilities services office and compliance officer to facilitate a universal design approach for all students. ${ }^{[23]}$ This universal design approach ensures all students are held to the same standard for meeting program outcomes. ${ }^{[23]}$ As nursing faculty cannot anticipate or possibly incorporate all conceivable formal accommodations, this close collaboration can facilitate the handling of academic accommodations as a more systematic approach. ${ }^{[23]}$ This systematic approach also ensures nursing faculty provide consistent disability-related accommodations as best practice for maintaining academic rigor and standards. ${ }^{[23]}$ However, the systematic approach is hypothetical and does not provide data or specifications on the process or effectiveness for the systematic approach. ${ }^{[23]}$ Therefore, while literature does exist about what accommodations can be used and have been implemented, further research is needed regarding the procedure by which aca-

Published by Sciedu Press demic accommodations are constructed by nursing faculty.

\subsection{Lack of understanding of the procedure of academic accommodation implementation}

While a significant body of literature exists in higher education regarding students with learning disabilities, literature on academic accommodations for learning disabilities in a classroom setting in nursing education is extremely limited. ${ }^{[12,14,19]}$ The lack of current research results in a lack of best practices for accommodating nursing students with learning disabilities. ${ }^{[15,22]}$ While nursing faculty have a high percentage of interaction with students with learning disabilities due to the increasing prevalence, a lack of understanding exists regarding how to provide academic accommodations to promote student success. ${ }^{[9,14,29,32]}$ Additionally, nursing faculty may have experienced academic accommodations, but few understand the procedure for how academic accommodations are implemented within a classroom setting. ${ }^{[17,23]}$ This lack of knowledge provides a vital rationale for the need for literature to guide faculty's understanding of the procedure and implementation of effective academic accommodations. ${ }^{[22,23,29]}$

One article was discovered that provided suggestions for a systematic approach as best practice when students request academic accommodations without compromising the academic rigor of a nursing program. ${ }^{[23]}$ However, the systematic approach is hypothetical and does not provide data or specifications on the process or effectiveness for the systematic approach. ${ }^{[23]}$ Therefore, nursing faculty have limited guidance when attempting to implement academic accommodations potentially affecting the success of nursing students with learning disabilities in the classroom setting. ${ }^{20,22]}$

\section{Discussion AND CONCLUSION}

A paucity of literature exists regarding the procedure in the classroom setting by which nursing faculty construct reasonable academic accommodations for undergraduate nursing students with learning disabilities. This scoping review uncovered beneficial information regarding faculty attitudes towards students with learning disabilities and previously used accommodations but did not provide a systematic method of the procedure in the classroom setting for accommodation implementation for students with learning disabilities. Without knowledge on how to systematically implement accommodations for nursing students with learning disabilities, inconsistent classroom accommodation practices that do not foster student success are likely to result. Therefore, the discovered available literature failed to answer the research question: What is the procedure in the classroom setting by which nursing faculty construct academic accommodations 
for undergraduate nursing students with learning disabilities? Consequently, additional research is needed to determine the procedure in the classroom setting by which nursing faculty construct academic accommodations for such students with learning disabilities.

\section{CONFlicts OF InTEREST Disclosure}

The author declares that there is no conflict of interest.

\section{REFERENCES}

[1] Baker K, Boland K, Nowik C. A campus survey of faculty and student perceptions of persons with disabilities. Journal of Postsecondary Education and Disability. 2012; 25(4): 309-329.

[2] National Center for Education Statistics. Students with disabilities at degree-granting postsecondary institutions. 2011. Available from: https://nces.ed.gov/pubsearch/pubsinfo.asp?pub id $=2011018$

[3] Abreu M, Hillier A, Frye A, et al. Student experiences utilizing disability support services in a university setting. College Student Journal. 2016; 50(3): 323-328.

[4] Hong BS. Qualitative analysis of the barriers college students with disabilities experience in higher education. Journal of College Student Development. 2015; 56(3): 209-226. https ://doi.org/10 $.1353 /$ csd. 2015.0032

[5] Reinschmiedt H, Sprong M, Dallas B, et al. Post-secondary students with disabilities receiving accommodations: A survey of satisfaction \& subjective well-being. Journal of Rehabilitation. 2012; 79(3): 3-10.

[6] Yssel N, Pak N, Beilke J. A door must be opened: Perceptions of students with disabilities in higher education. International Journal of Disability, Development, and Education. 2016; 63(3): 384-394. https://doi.org/10.1080/1034912X.2015.1123232

[7] Timmerman LC, Mulvihill TM. Accommodations in the college setting: The perspectives of students living with disabilities. The Qualitative Report, 20(10), 1609-1626.

[8] Cawthon S, Cole E. Postsecondary students who have a learning disability: Student perspectives on accommodations access and obstacles. Journal of Postsecondary Education and Disability. 2010; 23(2): 112-128.

[9] Murray C, Lombardi A, Wren C. The effects of disability-focused training on the attitudes and perceptions of university staff. Remedial and Special Education. 2011; 32(4): 290-300. https ://doi.org/ $10.1177 / 0741932510362188$

[10] National League for Nursing. Achieving diversity and meaningful inclusion in nursing education. 2016. Available from: http://www.nln.org/docs/default-source/about/visi on-statement-achieving-diversity.pdf?sf vrsn=2

[11] Newsham K. Disability law and health care education. Journal of Allied Health. 2008; 37(2): 110-115.

[12] Sharby N, Roush S. Analytical decision-making model for addressing the needs of allied health students with disabilities. Journal of Allied Health. 2009; 38(1): 54-62.

[13] Shpigelman C, Zlotnick C, Brand R. Attitudes toward nursing students with disabilities: Promoting social inclusion. Journal of Nursing Education. 2016; 55(8): 441-449. PMid:27459430 https : //doi.org/10.3928/01484834-20160715-04

[14] Ardary D. Nursing faculty experiences teaching students with learning disabilities (Doctoral dissertation). Retrieved from ProQuest. 2014.

[15] Betz C, Smith K, Bui K. A survey of California nursing programs: Admission and accommodation policies for students with disabilities. Journal of Nursing Education. 2012; 51(12): 676-684. https://doi .org/10.3928/01484834-20121112-01

[16] Dong S, Lucas M. An analysis of disability, academic performance, and seeking support in one university setting. Career Development and Transition for Exceptional Individuals. 2016; 39(1): 47-56. https ://doi.org/10.1177/2165143413475658

[17] Levey J. Attitudes of nursing faculty towards nursing students with disabilities: An integrative review. Journal of Postsecondary Education and Disability. 2014; 27(3): 321-332.

[18] Aaberg V. A path to greater inclusivity through understanding implicit attitudes toward disability. Journal of Nursing Education. 2012; 51(9): 505-510. PMid:22766074 https://doi.org/10.3928/01 484834-20120706-02

[19] Marks B, Ailey S. White paper on inclusion of students with disabilities in nursing educational programs for the California committee on employment for people with disabilities. 2014. Available from: http://www . aacn.nche.edu/education-resources/S tudent-Disabilities-White-Paper.pdf

[20] Marks B, McCulloh S. Success for students and nurses with disabilities: A call to action for nurse educators. Nurse Educator. 2016; 41(1): 9-12. PMid:26402910 https://doi.org/10.1097/NNE. 000000 0000000212

[21] May K. Nursing faculty knowledge of the Americans with disabilities act. Nurse Educator. 2014; 39(5): 241-245. PMid:24867075 https://doi.org/10.1097/NNE.0000000000000058

[22] Neal-Boylan L, Miller M. Treat me like everyone else: The experience of nurses who had disabilities while in school. Nurse Educator. 2017; 42(4): 176-180. PMid:27922900 https://doi.org/10.1 097/NNE. 0000000000000348

[23] Meloy F, Gambescia S. Guidelines for response to student requests for academic consideration: Support versus enabling response. Nurse Educator. 2014; 39(3): 13-142. PMid:24743179 https://doi.org/10.1097/NNE. 0000000000000037

[24] Troiano P, Liefeld J, Trachtenberg J. Academic support and college success for postsecondary students with learning disabilities. Journal of College Reading and Learning. 2010; 40(2): 35-44. https://doi.org/10.1080/10790195.2010.10850329

[25] Dupler A, Allen C, Maheady D, et al. Leveling the playing field for nursing students with disabilities: Implications of the amendments to the Americans with Disabilities Act. Journal of Nursing Education. 2012; 51(3): 140-144. PMid:22283155 https://doi.org/10.3 928/01484834-20120127-05

[26] Arksey H, O’Malley L. Scoping studies: Towards a methodological framework. International Journal of Science Research Methodology. 2005; 8(1): 19-32. https://doi.org/10.1080/136455703200 0119616

[27] Grant M, Booth A. A typology of reviews: An analysis of 14 review types and associated methodologies. Health Information \& Libraries Journal. 2009; 26(2): 91-108. PMid:19490148 https: //doi.org/10.1111/j.1471-1842.2009.00848.x 
[28] Levac D, Coloquhoun H, O'Brien K. Scoping studies: Advancing the methodology. Implementation Science. 2010; 5(1): 1-9. PMid:20854677 https://doi .org/10.1186/1748-5908-5-69

[29] Ashcroft T, Chernomas W, Davis P, et al. Nursing students with disabilities: One faculty's journey. International Journal of Nursing Education Scholarship. 2008; 5(1): 1-26. PMid:18454732 https: //doi.org/10.2202/1548-923X.1424

[30] Burgstahler S, Doe T. Improving postsecondary outcomes for stu- dents with disabilities: Designing professional development for faculty. Journal of Postsecondary Education and Disability. 2006; 18 : 135-145.

[31] Kolanko K. A collective case study of nursing students with learning disabilities. Nursing Education Perspectives. 2003; 24(5): 251-256.

[32] Kurth N, Mellard D. Student perceptions of the accommodation process in postsecondary education. The Journal of Postsecondary Education and Disability. 2006; 19(1): 71-84. 